\title{
Reflexiones historiográficas sobre la biografía
}

\author{
Historiographic reflections on biography \\ EDGAR DE JESÚS VELÁSQUEZ RIVERA \\ Universidad del Cauca (Colombia) \\ https://orcid.org/0000-0003-2438-3520 \\ edgarvelasquezrivera@gmail.com
}

\section{RESUMEN}

Como se sabe, desde la antigüedad clásica la biografía ha tenido una compleja evolución y suele definirse como la historia o el testimonio de la vida de una persona. La biografía es, ante todo, una construcción histórica, dando lugar ello a una rica polifonía en cada cultura. Aunque se le señala de ser una creación subjetiva donde la fantasía y la libertad comprensiva juegan un rol determinante, estimamos su enorme valía como recurso cognitivo en el conjunto de las Ciencias Humanas y Sociales, a lo cual pretende contribuir este artículo desde unas reflexiones historiográficas sobre tan importante género.

Palabras clave: biografía, sujeto, biógrafo, subjetividad, biografiado, testimonio, conocimiento.

\section{Abstract}

As is known, since classical antiquity, biography has had a complex evolution and is usually defined as the story or the testimony of a person's life. Biography is, above all, a historical construction, giving rise to a rich polyphony in each culture. Although it is pointed out to be a subjective creation where fantasy and comprehensive freedom play a determining role, we estimate its enormous value as a cognitive resource in the Human and Social Sciences as a whole, to which this article aims to contribute from some historiographical reflections on so important gender.

Keywords: biography, subject, biographer, subjectivity, biographed, testimony, knowledge.

\section{INTRODUCCIÓN}

Los objetivos de este artículo son presentar algunas reflexiones historiográficas sobre la biografía, al igual que describir, explicar y sistematizar probables tipos de la misma existentes en el mundo contemporáneo. Cada biógrafo trabaja desde específicas perspectivas conceptuales, juicios, prejuicios, subjetividades y metodologías que estima 
adecuadas y, por lo anterior, se ha configurado una compleja constelación de formas, sentidos y tipos de biografía que convierte a este género en un fértil terreno investigativo desde diversas disciplinas, explicación que permite comprender la relevancia de estas reflexiones historiográficas sobre la biografía.

En las mismas, se tuvo en cuenta, preferentemente, fuentes secundarias, consistentes en obras tanto de biógrafos como de autores cercanos a dicho género, de origen europeo, estadounidense y latinoamericano, quienes desde distintas épocas, tradiciones y disciplinas han contribuido en la construcción y consolidación de la biografía. En ese sentido, según José Luis Romero, hay dos polos del tipo biográfico: el polo arquetípico, por el cual la existencia individual aparece como representativa de los ideales colectivos y el polo individualista, enfatizando en los microcosmos del individuo ${ }^{1}$, aislado del contexto de su existencia.

Por su parte, Samuel Gajardo da cuenta de la existencia de otros tipos de biografía tales como la histórica, psicológica, tendenciosa, imparcial, auténtica, novelada y científi$\mathrm{ca}^{2}$. A las anteriores taxonomías se suma la propuesta por León Edel quien considera que existen biografías documental-tradicional, creativa e imaginada ${ }^{3}$. No obstante, desde nuestra perspectiva, identificamos nuevas variedades de biografías siendo las más relevantes la mediática, confesional, sectorial, integral, comparada, oral, crítica y desde abajo ${ }^{4}$.

Los múltiples tipos de biografía señalados son complementarios y, en ningún modo, excluyentes. La impronta o especificidad de cada uno está dada por el énfasis que el biógrafo ponga en su trabajo y esta especie de taxonomía no es un compartimento rígido, sino que, por contrario, permite establecer las múltiples conexiones entre las distintas modalidades de biografía, amplía el horizonte conceptual sobre el género biográfico y, por tanto, permite explorar nuevos ámbitos de acción del biógrafo.

En términos formales, este artículo, concordante con los objetivos, está dispuesto en tres acápites. El primero, muestra algunas reflexiones historiográficas sobre la biografía; el segundo, describe, explica y sistematiza probables nuevos tipos biográficos y, el tercero, detalla las conclusiones.

\section{REFLEXIONES HISTORIOGRÁFICAS SOBRE LA BIOGRAFÍA}

Los tipos biográficos (arquetípico e individualista) expuestos por José Luis Romero registran ciertas peculiaridades. En el primero es poco probable una personalidad con la amplitud y plasticidad para representar a un pueblo o ser la condensación de la idiosincrasia del mismo, dado el carácter unívoco de los individuos. Un sujeto encumbrado ante sus

1 Romero, José Luis. Sobre la biografía y la historia. Buenos Aires, Sudamérica, 1945, 44.

2 Gajardo, Samuel. Cómo expresar la vida de un hombre. O la manera de escribir una biografía. Santiago, Universo, 1944, 31.

3 Edel, León. Vidas ajenas. Principia Biographica. Buenos Aires, Fondo de Cultura Económica, 1990, 144.

4 Velásquez Rivera, Edgar. La biografía, Popayán, Diseño Gráfico e Impresiones, 2007, 45. 
semejantes como el representante de los intereses colectivos, generalmente actúa desde una perspectiva mítica y mesiánica. Uno de los riesgos del tipo biográfico del polo arquetípico es terminar tomando la vida de una persona como la historia de un país o una cultura.

Por su parte el polo individualista limita el conocimiento del biografiado, al sustraérsele del contexto. El polo individualista niega el carácter social, político y conflictivo del ser humano y ubica al sujeto por encima del bien y del mal. Esta forma de hacer biografía encapsula al sujeto e impide la comprensión de su vida con respecto a la urdimbre de todo tipo de relaciones, siendo un ejemplo de esta variedad de trabajos, la "Biografía Universal: antigua y moderna o historia por orden alfabético de la vida pública y privada de todas las personas distinguidas por sus escritos, acciones, talentos, virtudes o vicios"5.

No obstante, como casos paradigmáticos del primero de los casos, están los líderes de los procesos de liberación nacional quienes logran aglutinar a la mayoría de sus compatriotas alrededor de una causa común, como puede ser la independencia respecto a otra potencia. El personaje de la biografía correspondiente al polo arquetípico suele presentarse ante la historia como uno de los principales protagonistas de la fundación del Estado-nación en su país y como un líder de alcance mundial quien en su momento histórico incidió en el curso de los acontecimientos y por su carisma se convirtió en acicate para otros pueblos con idénticas problemáticas.

En el segundo de los casos, es decir, el del polo individualista, la biografía corresponde a los microcosmos del individuo, el estudio sobre un personaje dado se circunscribe a tiempos, espacios y hechos cortos y reducidos. La obra, Napoleón: una biografía íntima ${ }^{6}$ puede ser considerada un caso representativo de este tipo de biografía. En el contexto de la biografía del polo individualista, el sujeto inspirador del estudio parece anclado en el tiempo de su existencia vital, referida a espacios del ámbito familiar, desde el punto de vista de pocos sucesos. La biografía del polo individualista da la sensación como si el biografiado hubiese surgido por generación espontánea y su vida transcurriere en condiciones en las cuales el contexto poco o nada habría incidido. Uno de los rasgos de la biografía del polo individualista, consiste en presentar al biografiado como un personaje que, en forma solitaria, aislada y heroica, ha triunfado o sobresalido en condiciones generalmente adversas.

Las dos vertientes biográficas expuestas, tienen cierta cercanía con los tipos de biografía expuestos por Samuel Gajardo, puntualmente en lo que este autor considera como biografía histórica. Consiste la misma en una relación cronológica de los hechos en forma lineal, precisa y auténtica de la tradición, testimonios y documentos. La biografía

5 Biografía Universal: antigua y moderna o historia por orden alfabético de la vida pública y privada de todas las personas distinguidas por sus escritos, acciones, talentos, virtudes o vicios. (Traducción del francés al castellano, con adiciones y refundiciones por Javier de Burgos. Madrid: Impr. de Mateo Repullés, 1822, 3 volúmenes.

6 Cronin, Vincent. Napoleón: una biografía íntima. (Traducción, Anibal Leal). Buenos Aires: Vergara Grupo Zeta, 2003, 501. 
histórica es analítica y descriptiva ${ }^{7}$. Desde ese punto de vista, la biografía histórica es la acumulación de hechos, incluso aquellos de poca relevancia. Uno de los rasgos de la biografía histórica es el atiborramiento de detalles y la casuística discursiva, y una de sus virtudes está en el rigor cronológico permitiendo construir así un cuadro aproximado de la existencia de un sujeto, tal como ocurre con las biografías "Antonio Gramsci: del liberalismo al comunismo crítico"8 y "Bakounine: biographie".

La precisión de la cronología lineal de la biografía histórica hace que el biógrafo, eventualmente, no pueda cumplir con tal exactitud, bien por la ausencia de información o porque la misma es improcedente dada su naturaleza, pues podría desmitificar al biografiado, o aclarar episodios de la sociedad. La biografía histórica puede inducir al biógrafo a narrar episodios del diario vivir que, desconectados del universo cultural imperante, los tornará fatuos, terminando por empalagar la lectura de la biografía. La labor del biógrafo se reduce a lo instrumental, a lo operativo, no tiene mayor exigencia, pues la narración y la trama brillan por su ausencia.

En ese mismo sentido Gajardo aduce la existencia de la biografía psicológica ${ }^{10}$, una de cuyas muestras puede ser "Newman: ensayo de biografía psicológica"11 al igual que "Nietzsche in Turin: an intimate biography" 12 . La anterior variedad biográfica revela rasgos caracterológicos del sujeto y acumula datos suficientes para conocer la personalidad del biografiado. En ese marco suelen privilegiarse facetas como la vida pública, privada o sentimental del biografiado, haciendo énfasis en las reacciones del mismo frente a situaciones dadas. Por la vía de la biografía psicológica es posible comprender patologías y comportamientos atávicos de gobernantes, por cuyas acciones polarizan a la sociedad entre quienes los admiran u odian.

La biografía psicológica tiene un amplio campo de acción, en el sentido de poder incrementar las posibilidades de conocer a un sujeto, partiendo de uno o varios episodios familiares, individuales o sociales incidentes en la configuración de una personalidad dada. La biografía psicológica de un determinado personaje muestra su estado o sus estados mentales, o posibles traumas de infancia y la concomitante aparición en la adolescencia o adultez, como es el caso del Ensayo de biografía psicológica. En esa obra el objeto del libro es el de esbozar el retrato, sondear un alma y describir la vida íntima de Newman, quien fue predicador, novelista, polemista, filósofo y poeta. Es descrito como «Inteligencia escéptica y alma profundamente creyente» ${ }^{13}$.

7 Gajardo, Samuel. Op, Cit., 31.

8 Losurdo, Domenico. Antonio Gramsci: del liberalismo al "comunismo crítico". (Juan Vivanco, Traductor). Madrid: Disenso, 2015, 231.

9 Grawitz, Madeleine. Bakounine: biographie. Calmann-Lévy. 2000, 47.

10 Gajardo, Samuel. Op. Cit., 32.

11 Brémond, Henri. Newman: ensayo de biografía psicológica. (Versión castellana de Santiago Cunchillos Manterola). Buenos Aires, Desclée de Brouwer. 1947, 246.

12 Chamberlain, Lesley. Nietzsche in Turin: an intimate biography. St Martin's Press, 1997, 95.

13 Bremond, Henry. Newman. Ensayo de biografía psicológica. Buenos Aires, Desclée, 1947, 8. 
Por su parte la biografía tendenciosa, según Gajardo, tiene lugar cuando se inicia o se parte de una intención preconcebida ${ }^{14}$, hacia el ataque o la defensa, no importando que los resultados de la investigación sobre la vida del biografiado, demuestren lo contrario. En este tipo de biografía juega un determinante los prejuicios, juicios y subjetividades del autor, tal como ocurre en "Piñera: biografía no autorizada" 15 . Desde la biografía tendenciosa, el trabajo del biógrafo suele oscilar entre la censura y la alabanza y presenta los hechos de manera sesgada. Se utiliza para demostrar o invalidar tesis científicas, educativas, políticas. Los estudios biográficos desde la perspectiva tendenciosa no escapan a uno u otro rasgo, bien desde la apología diletante o desde la crítica corrosiva y son pocos los estudios ajenos a ambos extremos. Los personajes que polarizan a una sociedad con sus actos como un dictador, por ejemplo, al ser biografiados arrojan este tipo de biografía tendenciosa.

Quienes actúan desde la biografía tendenciosa, generalmente son individuos con algún tipo de vinculación afectiva con el personaje: copartidarios, colegas, descendientes, amigos, paisanos, subalternos o súbditos, unos con formación académica y otros sin ella, pero fuertemente motivados por intereses particulares. Desde la perspectiva apologética se le rinde culto a la personalidad del individuo, y desde la otra, es decir mediante la censura, la crítica y la descalificación, se recurre al expediente de la diatriba para ocultar o minimizar la vida y obra del biografiado. Una y otra tendencia limita y excluye posibles esferas desde las cuales se puede realizar un estudio como un todo con sentido, situando al personaje biografiado en su tiempo histórico.

La biografía tendenciosa de alabanza se inscribe en el marco de la historia apologética, es llamada la llamada historia de "bronce" o "reverencial", otros la denominan didáctica, conservadora, moralizante, pragmática, política, ética y monumental, sus características son bien conocidas ${ }^{16}$. Esta escuela historiográfica y en ella la biografía tendenciosa de alabanza, recoge los acontecimientos a menudo celebrados en fiestas patrias, en el culto religioso y en el seno de las instituciones; se ocupa de gobernantes, santos, sabios y caudillos, presenta los hechos como simples monumentos dignos de imitación y pretende aleccionar con historias ${ }^{17}$, especialmente a las generaciones jóvenes. A este tipo de biografía de bronce, la moral cristiana la tuvo como su principal vehículo de expre$\operatorname{sión}^{18}$. En este tipo de biografía considerado por Gajardo, encontramos similitud con lo expuesto por Romero.

Biógrafos afectos a esta forma de narrar las vidas, creen en la existencia de ejemplos gloriosos para emular, dejados por hombres de otras épocas. La recordación de su buena

\footnotetext{
14 Gajardo, Samuel. Op. Cit., 33.

15 Daza N, Loreto. Piñera: biografía no autorizada. Santiago de Chile; Penguin Random House, 2017, 150.

16 González, Luis. De la múltiple utilización de la Historia. En: Pereyra, Carlos et al. Historia, ¿Para Qué? 6 edición, México, Siglo XXI, 1985, 64.

17 Ibíd.

18 González, Luis. Op. Cit., 65.
} 
conducta sería el medio más poderoso para la reforma de las costumbres, pues según ellos las hazañas de los grandes hombres, bien contadas por los historiadores, harán de cada criatura un apóstol, un niño héroe, un ciudadano ejemplar ${ }^{19}$. Esta forma de comprender y trabajar la biografía, desemboca en que los acontecimientos son abordados de manera lineal y cronológica. El carácter de cientificidad está dado, supuestamente, por la fidelidad al dato y al detalle y no tanto por el análisis y la explicación de los mismos. El contexto político, ideológico, económico, cultural, geográfico, religioso y social usualmente no es tenido en cuenta para analizar y explicar el medio cultural. Cuando se trata de un político, en la biografía se le atribuyen capacidades y dones no necesariamente ciertos y el ser artífice de ideas, supuestamente resistentes al paso del tiempo y, en consecuencia, es reivindicada su vigencia.

Quienes trabajan desde el horizonte de la biografía tendenciosa para la alabanza, y tal vez por los mismos lazos afectivos con el personaje, con frecuencia caen en exagerados reconocimientos, cuando no en elaboraciones fantasmagóricas, en adjetivos y calificativos erosionando la credibilidad. Se sienten en permanente deuda con el biografiado y consideran una forma apropiada de empezar a saldarla, elaborando este tipo de trabajos expresando infinitos agradecimientos por algún favor recibido o por la simple amistad. Quien cultiva la biografía tendenciosa para de alabanza, no comprende, analiza, ni critica, sino por el contrario, a través de la narración justifica y defiende las acciones del biografiado y no le reconoce error alguno.

Por su parte, quienes optan por la biografía tendenciosa de censura consideran al biografiado como la piedra angular de todo el edificio del mal. De él parten, en él se incuban y a él llegan todas las tragedias, problemas o penurias de los pueblos. Se le hace responsable de cuanto no agrada a la ciudadanía. Sólo se le ve impregnado de vicios, defectos y taras y se cree, por parte del biógrafo, no existir parangón alguno para contrastar o comparar su perversión. Esta biografía tendenciosa de censura permite a la oposición del biografiado, validar sus principios, tesis y planteamientos políticos. De idéntico modo de la biografía tendenciosa de alabanza, la biografía tendenciosa de censura limita el horizonte comprensivo de la vida de un personaje, le gana a éste el debate en razón de su ausencia o de su muerte. El biógrafo al actuar así, se sacia contra su biografiado y más allá de escribir una biografía, termina confeccionando una especie de prontuario del mismo.

Desde un ángulo distinto al anterior, Gajardo anuncia la existencia de la biografía imparcial. Consiste en la estricta exhibición de los hechos de la vida de una persona, sin emitir juicios, solamente explicando los antecedentes y los móviles de los actos del biografiado $^{20}$. Supuestamente hay dos formas de ser parcial: primero por acción. El autor expresa sus juicios adversos o favorables, y segundo por omisión. El escritor omite consciente y deliberadamente algunas circunstancias importantes con el fin de destacar

\footnotetext{
19 Ibíd.

20 Gajardo, Samuel. Op. Cit., 35.
} 
la actuación del personaje o empequeñecerla. La imparcialidad consistiría en el no apasionamiento del autor por la comprensión del personaje. Pero debe tenerse en cuenta que, al igual como ocurre en la historia, en la biografía, cualquiera que sea su naturaleza, la imparcialidad no es posible. No obstante, la obra "Magallanes: el hombre y su gesta" ${ }^{21}$ del destacado biógrafo Stefan Zweig bien puede ser considera una especie de biografía imparcial, al igual que "The Great Physicists from Galileo to Einstein²2 de George Gamow.

El problema no es ser parcial o imparcial, lo negativo es ocultar la parcialidad desde una supuesta imparcialidad. La biografía imparcial no existe. Un biógrafo debe ser una persona apasionada por el objeto de la biografía, si no le infunde e inspira pasión la biografía, el resultado de su trabajo será precario e irrelevante. La pasión es el halo estimulante del biógrafo, es el espíritu que le insufla persistencia y perseverancia ante los obstáculos, le hace soñar e imaginar nuevos ámbitos comprensivos y las respectivas estrategias metodológicas y teóricas para hacerlo.

Una perspectiva cercana a la anterior, es la biografía auténtica. El mismo autor la circunscribe a la presentación de los hechos reales, sin alterarlos ${ }^{23}$. Se trata de una exposición lo más cercana posible a la manera como ocurrió la vida del biografiado, sin tergiversarlos y en forma secuencial. La biografía auténtica es la antítesis de la biografía novelada y no admite elaboraciones ficticias. Una muestra de biografía auténtica es "Martin Lutero: biografía auténtica" ${ }^{24}$. Desde la biografía auténtica se prefiere sacrificar hechos, cuando sobre éstos no hay certeza de su ocurrencia, son dudosos o contradictorios, en ese caso el biógrafo opta por hacer las aclaraciones del caso y deja al libre arbitrio del lector la aceptación de lo expuesto. Uno de los aspectos positivos de la biografía auténtica es no permitir poner en boca del biografiado cosas no dichas, o atribuirle hechos no realizados y de esa manera la biografía auténtica es un freno para el abuso eventual del biógrafo ante el biografiado, pues estos casos suelen registrarse en forma más reiterada de lo comúnmente aceptado.

Sin embargo, la biografía auténtica por su misma condición de aferrarse a los hechos, termina por convertirse en un frío corolario de información que, dispuesta en forma secuencial, nada o muy poco contribuye a una comprensión cabal de la vida de una persona. En sentido estricto, una biografía auténtica es uno de los momentos de cualquier tipo biográfico, en su fase de recolección de información preliminar para el biógrafo configurar un plano o mapa conceptual y sobre esa malla inicial, empezar a tejer la vida de la persona. La biografía auténtica es insípida, no atrapa al lector, no tiene trama narrativa, la información está diseminada a manera de una lista de episodios, generalmente desconectados entre sí y sin ninguna articulación con el mundo circundante.

21 Zweig, Stefan. Magallanes: el hombre y su gesta. (Traducción de Editorial Juventud). Barcelona: Random House Mondadori, 2005, 190.

22 Gamow, George. The Great Physicists from Galileo to Einstein. Dover Publications Inc., 2003, 126.

23 Gajardo, Samuel. Op. Cit., 35.

24 Sociedad de Publicaciones Religiosas. Martin Lutero: biografía auténtica. Madrid: Sociedad de Publicaciones Religiosas, 1893, 107. 
Caso distinto es el de la biografía novelada, también expuesta por Gajardo. Consiste en una trama, con un argumento imaginado ${ }^{25}$. Es una transición entre la biografía y la novela. El caso más emblemático lo constituye "Raíces de arena y olvido: biografía y autobiografía novelada de las familias Jacob Bendeck, Abdelnour Salamé y Jacob Abdelnour $^{26}$. El personaje actúa en episodios y aventuras, mezcla realidad e inventiva. La trama novelesca cautiva y atrapa al lector. Uno de los inconvenientes de la biografía novelada, es determinar hasta dónde va lo verdadero y lo ficticio. Parte de la crítica sobre la biografía proveniente del mundo de los historiadores y de la historiografía en general, se instala en el cuestionamiento hacia algunos rasgos novelescos de no pocas biografías. En ese caso se ataca a la biografía como género historiográfico por su falta de rigor y laxitud extrema, contrario a lo característico de la investigación histórica propiamente dicha. Por conducto de la biografía novelada ${ }^{27}$, autores provenientes de las más diversas disciplinas han incursionado en el campo de la biografía, en algunos casos haciendo uso de un considerable acopio de información sobre el biografiado y, en otros, con una mínima información sobre el mismo elaboran tramas cautivantes.

La trama novelística trasladada a la biografía es una de las claves explicativas del éxito de algunas biografías y, por tanto, los purismos cientificistas de algunos biógrafos deben dar paso a la oxigenación del género biográfico desde la novela. La biografía tiene un campo de acción preciso, así como la novela, aunque algunas novelas terminan inspirándose en hechos históricos y en vidas de personajes singulares y logran desde su perspectiva, acercar al lector al conocimiento de la historia. Tal es el caso de la novela romántica María, al permitir conocer parte de la historia colombiana del siglo XIX, en lo relacionado con el esclavismo, las condiciones de vida, las guerras civiles y el régimen de tenencia de la tierra.

Sobre este mismo tópico, León Edel se pregunta

¿Son las biografías una forma de ficción? Algunos críticos así lo creen, mas están equivocados. En una novela, el novelista sabe todo acerca del héroe o la heroína. Sus personajes son de su propia invención y decide la suerte de ellos. Los novelistas son omniscientes; los biógrafos nunca lo son. Los personajes existen; los documentos existen, son los datos "dados" a un escritor de vidas. No pueden alterarse. Alterar es desfigurar. Un biógrafo puede meditar sobre los hábitos y condiciones de los personajes; puede estudiar su psicología, pero medita acerca de personas preexistentes... ${ }^{28}$.

Los biógrafos al narrar una vida deben abstenerse de las elucubraciones y de los

25 Gajardo, Samuel. Op. Cit., 35.

26 Jacob Abdelnour, Ruth Elsa. Raíces de arena y olvido: biografía y autobiografía novelada de las familias Jacob Bendeck, Abdelnour Salamé y Jacob Abdelnour. Santiago, 2008, 110.

27 Magris, Claudio. Biografía y novela. En, Revista de Occidente. No 220. Madrid. Septiembre 1999, 23.

28 Edel, León. Op. Cit., 10. 
recursos fantasmagóricos, así como de tomarse por asalto al biografiado y pensar, actuar y decidir por él. El novelista lo hace, pero si el biógrafo lo hiciese, se estaría asemejando al anatomista quien al diseccionar un cadáver, conoce sus partes y decide sobre las mismas. El biógrafo se desenvuelve en una cultura y le pertenece al lenguaje, más que éste a él.

...nunca debemos olvidar que, igual que otros artistas de la literatura, el biógrafo trabaja con palabras. Un novelista puede crear conversaciones imaginarias, pero un biógrafo solamente puede valerse de una conversación cuando ésta ha quedado registrada en notas y minutas o en cintas. La narrativa biográfica es cautelosa cuando recurre a la charla de sobremesa. Se vale de residuos de la vida: listas de lavandería, facturas sin pagar, fragmentos de cuentas, notas, murmuraciones, recuerdos...Esto sugiere que en la mayor parte de los casos las vidas están compuestas como si fuesen mosaicos. Los mosaicos, antes de quedar acomodados, no son ficción; son un cúmulo de trozos pequeños de realidad, ordenados para formar una imagen. El peligro de la ficción radica en una disposición caprichosa de estas piezas de realidad ${ }^{29}$.

En este caso es de crucial importancia el cuidado a tener con la información recopilada sobre el biografiado, no sólo para la narración en sí, sino porque un descuido u omisión de la información y su significado, puede falsear en todo o en parte la vida estudiada.

A propósito de la novela y de considerar al biógrafo como un artista de la literatura, la biografía, desde ese punto de vista es definida como «un arte noble y aventurado, tan noble como la elaboración de retratos pintados, poemas, estatuas. Sabemos cómo un pintor puede dar voces a un muro completo; y un escultor, con habilidad con el cincel y con su mirada, puede dar vida duradera a la arcilla. De igual modo, un biógrafo moldea a un hombre o una mujer a partir de documentos y palabras ${ }^{30}$, lleva a la perfección una vida narrada teniendo como base esos documentos. El carácter artístico del biógrafo se forja y pule en proporción directa al cultivo de la palabra escrita y convierte a ésta en un insumo esencial para su labor y así como varios escultores, pintores y novelistas de una misma tradición o de distintas escuelas se interesan por temas afines, sin ello suponer similares resultados. Los biógrafos formados en distintas escuelas del pensamiento también pueden coincidir en interesarse por un mismo personaje, y ello no necesariamente arrojará unos mismos resultados, por el contrario, la disparidad de criterios de los biógrafos sobre un personaje dado, los compele a refinar sus investigaciones y estilo, y la biografía desborda el ámbito del público especializado.

Tal es el caso de la biografía científica. En este tipo de biografía se parte de la sociedad correspondiente y para tal efecto, tiene en cuenta los factores hereditarios y 
ambientales $^{31}$, según lo manifiesta Gajardo. Las investigaciones adelantadas por los científicos sobre distintos tópicos, son importantes fuentes para quien decida realizar una biografía científica como en efecto actuó Ott, Hugo respecto a su trabajo biográfico titulado "Martin Heidegger: en camino hacia su biografía" 32 o incluso la biografía titulada "Descartes: a biography" ${ }^{33}$. La biografía científica además de ser sintética, es esencialmente educativa, porque con su método genético nos da a conocer el determinismo de la conducta humana; las causas de los errores, de los fracasos y de los triunfos ${ }^{34}$. La biografía científica debe explicar el porqué de las reacciones, sentimientos, hábitos y comportamientos. Desde la perspectiva de la biografía científica, es posible demoler mitos y creencias.

Es preciso señalar que los tipos de biografía sugeridos por Romero (arquetípico e individualista) guardan una estrecha relación con lo que Gajardo denomina biografía imparcial, auténtica e incluso novelada) y con la biografía documental tradicional expuesta Edel. En toda biografía existe algo de novela, se basa en documentos y versa sobre un sujeto en particular. Es evidente que los anteriores tipos de biografía y todos en general, en lo concerniente a sus respectivas clasificaciones son, usualmente, materia de constante controversia dado que cada autor o lector actúa desde precisos cánones axiológicos que le indican los criterios de verdad, objetividad e incluso de cientificidad.

A los anteriores tipos sobre la biografía, se suman los identificados por León Edel $^{35}$. Para este autor existen dos tipos de biografía. La biografía documental-tradicional, entendida como una obra integrada; en la que el biógrafo ordena el material permitiendo escuchar la voz del sujeto de manera constante, como ocurre en el caso de Miguel Castillo Didier quien al elaborar la biografía titulada "Juan Bautista Plaza: una vida por la música y Venezuela (ensayo de biografía documental)"36, actuó de ese modo.

En segunda instancia, la biografía creativa-imaginada consiste en la argumentación literaria, como algo semejante al retrato del pintor. Aquí la imagen está un poco más circunscrita; se bosqueja con esmero y se coloca un marco a su alrededor. En este tipo de biografía los materiales se funden y el biógrafo está presente en la obra como el narrador omnisciente, tal como se infiere en "Josyane Savigneau, la invención de una biografía"37 y en "Albert Camus: Nouveaux regards sur sa vie et son oeuvre" 38 .

31 Gajardo, Samuel. Op. Cit., 31.

32 Ott, Hugo. Martin Heidegger: en camino hacia su biografía. (Traducción Helena Cortés Gabaudan). Madrid: Alianza, 1992, 207.

33 Clarke, Desmond M. Descartes: a biography. Cambridge University Press. 2006, 122.

34 Gajardo, Samuel. Op. Cit., 32.

35 Edel, León. Op. Cit., 152.

36 Castillo Didier, Miguel. Juan Bautista Plaza: una vida por la música y Venezuela (ensayo de biografía documental). Caracas: Instituto Latinoamericano de Investigaciones y Estudios Musicales Vicente Emilio Sojo. 1985, 164.

37 Jiménez, Gustavo. Josyane Savigneau, la invención de una biografía. En: La Época (Diario: Santiago, Chile). Agosto 7 de 1992, 7.

38 Payette, Jean-Francois. Lawrence, Olivier. Albert Camus: Nouveaux regards sur sa vie et son oeuvre. Presses de l’Université du Québec. 2007. 
En estas obras se nos ofrece nítidamente la visión del biógrafo sobre el sujeto. Los documentos rara vez son citados. En una biografía de esta naturaleza se tiende a tomar prestado los métodos de la novela sin convertirse, sin embargo, en ficción, de igual modo la biografía no se interesa por una cronología estricta, puede ir hacia atrás y hacia delante de una vida dada, busca separar escenas o valerse de incidentes triviales para arrojar luz sobre el carácter. En síntesis, puede concebirse el primer tipo de biografía como el de una crónica; el segundo es pictórico; y el tercero narrativo-pictórico o novelístico. Al anterior bosquejo historiográfico se suman nuevas perspectivas o tipos biográficos que, en modo alguno serían excluyentes, sino complementarios.

\section{PROBABLES NUEVOS TIPOS BIOGRÁFICOS}

A los diversos tipos biográficos identificados por los tres autores precedentes, se agregan otros que, desde nuestra perspectiva existen tales como la biografía mediática, confesional, sectorial, integral, comparada, oral, crítica ${ }^{39}$ y desde abajo. Este último tipo de biografía, de reciente uso en comunidades comparativamente vulnerables, ha abierto al género biográfico novísimos alcances.

La biografía mediática, es la producida y difundida a través de los medios masivos de comunicación como radio, prensa, televisión, cine e internet. Ese tipo de biografía se divide en dos: las realizadas por biógrafos formados y la producida por quienes no lo son, y su uso es el de un artefacto para sustentar mensajes. La primera tiene cierto rigor, mientras la segunda no tanto. En el primero de los casos, el biógrafo encuentra en los mencionados medios, excelentes espacios para la difusión de las biografías, a parte de la presentación convencional en los libros, revistas y magazines. Una biografía puede inspirar una película y el biógrafo puede hacer las veces de director o productor o, en su defecto, la persona que contribuye con el conocimiento biográfico.

De análoga manera, los contenidos de las biografías y el trabajo del biógrafo, pueden ser llevados a la televisión, publicados en la prensa por entregas o capítulos, como también, ser transmitidos por la radio. No se trata de desplazar al libro, sino de complementar la labor informativa y formativa del biógrafo. La biografía una vez publicada como libro, puede presentarse en cada una de las formas de comunicación mencionadas y, además, al llegar a más audiencia, genera mayor impacto. Desde esta perspectiva, la biografía no es un medio, sino un fin como puede ser el del conocimiento.

En el segundo de los casos, es decir, la biografía producida por biógrafos no formados, es elaborada en un tiempo récord para sustentar una información, la biografía aquí no es un fin sino un medio para impactar y generar reacciones, es un apoyo para entregar una información más completa sobre un episodio o personaje y tal vez por esta razón,

39 Velásquez Rivera, Edgar. Op. Cit., 45. 
dicho tipo biográfico adolece de profundidad, precisión y rigor analítico. Tal es el caso de los espacios dedicados a la farándula donde actores, cantantes y actrices son el centro de atención y sobre ellos se elaboran biografías, pequeñas por cierto, pero con una alta proporción de sensacionalismo, siendo lo predominante los escándalos, sin diferenciar la vida pública de la privada.

Los escándalos sexuales, la vida sentimental y las relaciones de pareja, suelen ser las bases constituyentes este tipo de biografías, por cierto con una enorme demanda, especialmente de aquél mundo alienado cuando sufre y llora por las desventuras de sus personajes predilectos. La biografía mediática de este tipo le da la razón a los detractores del género biográfico en general cuando lo catalogan, sin ningún discernimiento, como una labor de hienas. Otros personajes predilectos de la biografía mediática, son los deportistas a quienes los comunicadores, en virtud de un desempeño excepcional, los describen como estrellas sin parangón alguno en la historia y, con esa misma facilidad e irresponsabilidad, si el rendimiento declina, sin ningún empacho vituperan de ellos sin contemplación alguna. La biografía mediática del primer tipo puede llegar a ser una fuente confiable, no así la del segundo. Por la naturaleza del personaje que inspira la biografía realizada por Víctor Herrero, la metodología empleada, el contenido, los propósitos y las fuentes, su texto "Agustín Edwards Eastman: una biografía desclasificada del dueño de El Mercurio ${ }^{40}$ es un claro ejemplo de la biografía mediática.

De análoga manera identificamos la existencia de la biografía confesional ${ }^{41}$. Como su nombre lo indica, es la realizada por un confesor. El confesor puede ser laico o religioso. El juez como confesor laico investiga a un sindicado de haber cometido un delito, e intenta conocer su vida familiar, pública y privada. Dicho funcionario construye una biografía, no necesariamente para publicarla sino como un insumo para tener una imagen global de la persona sindicada de la comisión de un delito y así tener mayores elementos de juicio para decidir. Con alguna frecuencia este tipo de biografías son publicadas a lo largo del proceso judicial a través de los medios de comunicación o, una vez ejecutoriada la sentencia, sirven de base para biografías de mayor alcance que, entre otras cosas, aparte de la vida misma del sujeto, permite conocer cuestiones inherentes al funcionamiento y administración de justicia.

Por su parte el confesor religioso es el sacerdote ante quien un feligrés confiesa sus pecados y el clérigo le somete a un cuestionario sobre su vida, con la pretensión de auscultar la forma, los contenidos y las circunstancias del pecado. La biografía confesional desde el punto de vista religioso es un efectivo mecanismo de control social, ético, moral, ideológico y cultural. Este tipo de biografía confesional juega con la dupla pecado/perdón, el creyente al pecar confía en el perdón de su falta tras comprometerse a enmendar su comportamiento y, por esta vía, reprime la mente y el cuerpo de las personas en todo

\footnotetext{
40 Herrero, Víctor. Agustín Edwards Eastman: una biografía desclasificada del dueño de El Mercurio. Santiago de Chile: Penguin Random House, 2014, 318.

41 Velásquez Rivera, Edgar. Op. Cit., 62.
} 
sentido, pero a su vez, realza la imagen de los principales líderes espirituales y los pone, sin mácula alguna, en comparación con los demás mortales, en cuyo contexto se inscribe tanto la "Biografía del Papa Pío IX"42 como la obra "Jean-Paul II: la biographie"43.

En las primeras décadas del siglo XXI, el abanico de conductas pecaminosas, decretadas por la Iglesia Católica y desde las cuales por la vía de la confesión se ejerce control social, político, ético, biológico y moral, se ha ampliado, al punto de catalogarse pecado no pagar impuestos, además de la condena férrea al aborto y al matrimonio entre parejas del mismo sexo. La Iglesia Católica aquí, como probablemente en otros ámbitos, asume una posición contradictoria: por un lado defiende a ultranza a sus miembros comprometidos en casos de homosexualismo y pederastia, y por otro lado, esas mismas prácticas en los laicos, son condenadas acremente.

Así mismo encontramos la biografía sectorial ${ }^{44}$. En ella el biógrafo, elige del biografiado, una o dos facetas. La de pensador o intelectual, por ejemplo. Entonces es común encontrar títulos alusivos a la biografía intelectual, o al pensamiento de alguien sobre un tópico específico. La limitación de esta biografía sectorial, consiste en presentar al biografiado como un sujeto desconectado de las demás esferas de la vida. Este tipo de biografía es una fracción del conocimiento de la vida de una persona, quien no incorpora ni valora la totalidad de la praxis humana, sino sólo una parte de la misma, supuestamente la más relevante para el público. Una de las deficiencias de la biografía sectorial es presentar al biografiado, como una persona ascética imbuida en su campo de acción y no alcanzada por los acontecimientos de la política, la cultura y el diario vivir; además de hacer énfasis en un método y un tipo de fuentes tales como las fotografías que, de manera cronológica, denotan la evolución del biografiado tal como se puede observar en la "La biografía en fotos del Presidente Chiang Kai Shek"45.

Como correlato del anterior tipo biográfico, está la biografía integral ${ }^{46}$. Pretende incorporar el mayor número posible de facetas del biografiado, a efectos de ofrecer un cuadro lo más completo posible de su vida, siendo la obra "Lincoln: biografía completa e ilustrada del más glorioso presidente norteamericano ${ }^{47 "}$ el caso más revelador de este tipo de biografía.

La biografía integral no excluye hacer énfasis en los aspectos más descollantes del biografiado, pero tampoco desconoce las otras esferas tanto privadas como públicas, pero el sentido de lo integral no es sinónimo de incorporar, radicalmente, todas las facetas por las cuales transcurre una vida, se trata de tener la entereza y la decisión para desechar lo

42 Veuillot, Louis. Biografía del Papa Pío IX. Madrid: Impr. de la Esperzanza. 1863, 40.

43 Vircondelet, Alain. Jean-Paul II: la biographie. First. 2004, 75.

44 Velásquez Rivera, Edgar. Op. Cit., 65.

45 Tong, Hollington K. La biografía en fotos del Presidente Chiang Kai Shek. China: Government Infomation off, 1972, 122.

46 Velásquez Rivera, Edgar. Op. Cit., 67.

47 Basler, Roy Prentice. Lincoln: biografía completa e ilustrada del más glorioso presidente norteamericano. México: Limusa, 1966, 113. 
fatuo y lo poco interesante para la comprensión de la vida. ¿De qué manera el estado de salud de los gobernantes decimonónicos incidió en la inestabilidad de sus países, y cómo aquella estuvo asociada a las prácticas médicas y alimenticias de la época? El biógrafo puede partir de preguntas de esta naturaleza o de otras según su criterio, pero en todo caso como miras a permitirle deshilvanar el ovillo de la trama de la vida.

La biografía integral, por su misma connotación, puede incorporar en el discurso narrativo recursos tales como fotografías de las distintas etapas de la vida o aquellas de eventos especiales, copias de documentos desde cuya información el biógrafo se apuntala para avanzar en la narración. La proporción de estos refuerzos debe ser equilibrada para no saturar la biografía con dichos documentos, éstos deben ser explicados por el biógrafo para facilitar la comprensión de la biografía por parte del lector y su ubicación puede ser intercalada o puesta al final a manera de anexo. En cualquiera de los casos, la elección de qué se incorpora y qué no, es de enorme importancia, pues a veces la narración del pasaje es confusa, contradictoria o superficial y, cuando ello ocurre, un documento estratégicamente seleccionado puede decirle más al lector y sobrepasar la misma narración. La procedencia de tales documentos también debe ser aclarada.

El tipo de biografía integral así sustentado, permite mencionar la biografía comparada. Este fue el tipo biográfico privilegiado por Plutarco ${ }^{48}$. El biógrafo puede optar por igual metodología e introducir modificaciones como la narración de las vidas y la comparación de manera simultánea. Independientemente de cuál estrategia metodológica tome el biógrafo deberá, en todo caso, informar por qué se compara y desde qué perspectivas, horizontes o puntos de vista, aparte de referirse a la diacronía y la sincronía como conceptos fundamentales en la comparación biográfica.

Como se sabe, el método comparativo permite hacer descripciones más profundas, al tomar los casos por separado, los estudia y luego los compara con sus pares o unidades identificadas para tal efecto. Coadyuva a la formulación de nuevos conceptos, ya que los estudios parten de casos particulares y no generales, analizando las especificidades de los primeros. Contribuye a la elaboración de nuevas hipótesis, problemas, teorías y metodologías, al franquear las existentes erigidas sobre casos generales. Permite un mejor conocimiento de las vidas de las personas, pues se toman casos considerados potencialmente paradigmáticos del género. Facilita una mejor comprensión a través del examen cuidadoso de un pequeño número de casos, a partir de los cuales se puede proceder a postular algunas generalizaciones sobre las biografías. Al enfocar pocos casos se logra mayor profundidad, se evitan generalizaciones aceptadas sin ninguna crítica y hace parte de tal perspectiva "Los doce Césares"49.

48 Plutarco. Vidas paralelas I. Teseo-Rómulo. Licurgo-Numa. Introducción general, traducción y notas por Aurelio Pérez Jiménez. Madrid, Gredos, 2000, 72.

49 Suetonio Tranquilo, Cayo. Los doce Césares. (Norberto Castilla, Traductor). Madrid: Páez y Cía, 1917, 213. 
También ayuda a identificar los aspectos o variables más importantes a tener en cuenta en los casos a comparar o a analizar. Por medio del método comparativo se evalúan las explicaciones existentes sobre un fenómeno, se analizan de manera crítica a partir de nuevas teorías, enfoques, conceptos o perspectivas. Permite un examen sistemático entre casos. Muestra la validez o las fisuras de un modelo de conceptos en el examen de un número de casos dado, posibilitando la confirmación de la vigencia de los conceptos, o a la necesidad de crear otros. Por medio del examen de dos o más casos, al establecer las diferencias, se logra un marco de interpretación de cómo los procesos se desenvuelven de distintas maneras, dentro de cada contexto. El contraste de contexto, es fundamental ${ }^{50}$. Las posibilidades ofrecidas por el método comparativo a la biografía son inmensas y pueden dar lugar a trabajos que, desde el punto de vista historiográfico, aún esperan un biógrafo.

Desde la perspectiva metodológica de la biografía comparada se puede arribar a algunas generalizaciones mediante la observación de recurrencias, mientras las diferencias nos permiten establecer lo considerado como único a cada uno de los biografiados y su particular dinámica. La comparación supone tanto similitudes como diferencias, por eso se parte de un conocimiento cabal de cada biografiado tan bien como sea posible, para luego poder hacer la comparación. No son biografías paralelas, aunque puede serlo antes de la comparación. Mediante la comparación se puede establecer la particularidad. La comparación revela las regularidades. La comparación permite revelar fenómenos que de otra manera habrían pasado desapercibidos. La comparación ayuda a establecer hechos para los cuales no existe suficiente información en las fuentes ${ }^{51}$. Los principales objetivos de la comparación son la formulación de generalizaciones válidas a través de la observación de recurrencias, así como demostrar las particularidades a través de la observación de diferencias y la manera de ayudar a establecer explicaciones causales ${ }^{52}$.

Otra de las virtudes de la biografía comparada consiste en permitir hacer comparaciones cercanas y distantes, tanto en el tiempo como en el espacio ${ }^{53}$; diacrónicas, donde las unidades se comparan en diferentes puntos a lo largo de un eje temporal y sincrónicas, donde las unidades se comparan en un momento dado ${ }^{54}$, de tal manera la vida de una persona, como objeto de estudio, puede ser abordada desde diversos ángulos, a efectos de lograr un conocimiento integral del biografiado. En todo caso, desde la perspectiva teórica de la biografía comparada se debe aclarar cómo definir y delimitar las vidas de los biografiados, cómo hacer periodizaciones y cómo considerar los factores conectados y desarrollados paralelamente, así como las consecuencias de esta situación para los análi-

50 Collier, David. Método comparativo. En: Revista Uruguaya de Ciencia Política. $N^{\circ}$ 5. Instituto de Ciencia Política. Facultad de Ciencias Sociales. Universidad de la República. Montevideo, 1992, 21.

51 Morner, Magnus. Ensayos sobre historia latinoamericana. Biblioteca de Ciencias Sociales. Volumen 37. Universidad Andina Simón Bolívar. Quito, 1992, 100.

52 Morner, Magnus. Op. Cit., p. 101.

53 Morner, Magnus. Op. Cit., p. 104.

54 Ibid. 
sis generales y para estudiar las diversidades ${ }^{55}$. Las comparaciones se llevan a cabo entre entidades poseedoras de atributos compartidos o similares, y en parte, no compartidos ${ }^{56}$. En el marco de la biografía comparada se deben subrayar tanto las similitudes como las diferencias, buscar las diferencias en los contextos similares y las analogías en los sistemas diferentes ${ }^{57}$. El tipo ideal ${ }^{58}$ también facilita la comparación biográfica.

Así expuesto el tipo de biografía comparada, el mismo es un relevante recurso investigativo para la biografía oral. El tipo de biografía oral es definido como la indagación realizada por un sujeto sobre un problema específico del conocimiento histórico, como puede ser la vida de una persona, a partir de fuentes orales de quienes participaron de manera directa en sucesos relacionados con el problema planteado ${ }^{59}$. De la biografía oral, puede identificarse, entre otras, las siguientes características: es una biografía palpitante transmisora de expresiones, cosmovisiones, luchas, resistencias y acciones cotidianas; en dicha biografía cuenta la subjetividad, entendiendo por subjetividad el conjunto de percepciones emanadas de un individuo o grupo sobre un determinado proceso histórico originando una cosmovisión propia; la biografía oral es una forma de sentir e interpretar los hechos, es una biografía de atmósferas construida entre biografiados y biógrafos y se constituye en un valioso dispositivo para la preservación de la memoria de los pueblos en sus luchas integradas al arte como ocurre con la "Biografía oral: los rostros de Menecio Antúnez". ${ }^{60}$

A través de la biografía oral se consigue reconstruir la atmósfera de cómo actores sociales vivieron y sintieron un suceso, es decir, las condiciones de su recepción, las simbologías en juego, sus reacciones, motivos, pasiones y sentimientos. En la biografía oral, el biografiado es la principal fuente de información, aunque no la única, pero obviamente puede serlo. La biografía oral es una historia contemporánea, reciente o inmediata ${ }^{61}$. Sus posibilidades cronológicas están determinadas por la existencia vital de los protagonistas. El biógrafo no desaparece en la biografía oral ante la presencia del biografiado. El biógrafo organiza el material, busca los testimonios, interroga, guía las entrevistas, selecciona los resultados, reconstruye la información, la confronta con otras fuentes y reelabora los datos suministrados. La biografía oral se constituye en un recurso historiográfico válido, cuando permite conocer la lectura sobre el biografiado por parte de los contemporáneos del mismo, independientemente del concepto se tenga de él.

55 Morlino, Leonardo. Problemas y opciones en la comparación. En: La comparación en las Ciencias Sociales. Giovanni Sartori y Leonardo Morlino (eds.). Madrid, Alianza, 1994, 22.

56 Sartori, Giovanni. Comparación y método comparativo. En: La comparación en las Ciencias Sociales. Giovanni Sartori y Leonardo Morlino (eds.). Madrid, Alianza, 1994, 35.

57 Sartori, Giovanni. Op. Cit., 40.

58 Judith Janoska-Bendl, Max Weber y la sociología de la historia, Buenos Aires, Sur, 1972, $30-36$.

59 Vega Cantor, Renán. Historia: conocimiento y enseñanza. Bogotá, Antropos, 1988, 187.

60 Aburto Prieto, Fabiola. Biografía oral: los rostros de Menecio Antúnez. En: La Segunda (Diario: Santiago de Chile) Noviembre 30, 2019, 16.

61 Piña, Carlos. Sobre las historias de vida y su campo de validez en las ciencias sociales. Documento de Trabajo. Programa Flacso. Santiago de Chile. No 319. Santiago. Octubre de 1986, 29. 
A los anteriores tipos de biografía es procedente anexar la biografía crítica ${ }^{62}$. Se parte del criterio según el cual, ésta debe ser también la historia de la época del ciclo vital del personaje, pues al estudiar y conocer la época vivida por el biografiado, se tiene mayor información y elementos de juicio para hacer una biografía. El estudio de la época arrojará información sobre las prácticas alimenticias, las costumbres familiares, el rol de la religiosidad, las teorías y prácticas pedagógicas en boga, las materias de conocimiento establecidas por las instituciones, las comunicaciones, los conflictos sociales, la dinámica económica, las expresiones culturales, los valores, las enfermedades agobiantes de la sociedad, las instituciones, el desarrollo de la ciencia, la cultura, la ciencia, la tecnología, los gobiernos, los modelos de desarrollo, las relaciones internacionales, las controversias ideológicas, el clima, los desastres naturales, las pestes, el ocio, el trabajo, los temores y las esperanzas.

Conocer la época vivida por el biografiado es entender el contexto en el cual se desenvolvió. Es advertir el cúmulo de circunstancias determinantes en la decantación de su personalidad. Es percatarse del escenario donde actuó el biografiado en familia, comunidad, sociedad e instituciones. Tratándose de una biografía por cuyo medio las regiones puedan contar su historia, la comprensión de la época histórica de una región o del espacio receptáculo de parte de la vida el biografiado, debe ser articulado al conocimiento del país, del continente y del mundo, estableciendo las relaciones entre sí. De esta manera se identifican las influencias externas sobre la vida del biografiado, en ocasiones, más fuertes que las de su región o país. Así por ejemplo, los viajes, los libros y la correspondencia del biografiado pueden arrojar pistas sobre sus contactos con el mundo exterior.

La biografía crítica guarda distancia del «complejo de Adán», consistente en creer al biografiado como el principio de todas las cosas y la biografía producida sobre él, la única e insuperable. La biografía crítica desbroza caminos para nuevas biografías, desde distintos enfoques y metodologías. La biografía crítica reconstruye el ambiente contextual vivido por el biografiado, para comprender y explicar los alcances y limitaciones de su praxis, así como para valorar sus aportes y determinar las perspectivas de sus obras. La biografía crítica no es censura, es una alternativa propiciadora del conocimiento de una época dada, para estudiar sobre ella, la vida del sujeto elegido por el biógrafo como ocurre con "Kavafis: una biografía crítica"63.

La biografía crítica se apoya en algunas tesis de Karl Popper, según las cuales «Nuestra ignorancia es seria e ilimitada» y la «La lógica del conocimiento tiene que discutir esta tensión entre conocimiento e ignorancia»; de igual modo «El conocimiento parte de problemas y la tensión entre conocimiento e ignorancia conduce a problemas y soluciones tentativas. La tensión nunca es superada». Por tanto «No podemos despojar al científico de su partidismo sin, al mismo tiempo, despojarlo de su humanidad, y no pode-

62 Velásquez Rivera, Edgar. Op. Cit., 73.

63 Liddell, Robert. Kavafis: una biografía crítica. Barcelona: Ediciones Ultramar, 1989, segunda edición, 155 . 
mos suprimir o destruir los juicios de valor del científico sin destruirlo como ser humano y como científico» lo cual calza perfectamente con el caso del biógrafo quien en su praxis trabaja con teorías, es decir, con sistemas deductivos en un intento de explicación ${ }^{64}$ de la vida del biografiado.

La verdad es el resultado de la crítica, si no hay crítica tanto sobre los problemas y sus soluciones tentativas como también sobre las teorías o sistemas deductivos, no hay verdad y la verdad es temporal como son temporales las soluciones a los problemas. Lo admitido hoy como verdad, mañana ya no lo es, y no lo es por la simple inercia del tiempo, sino por la acción constante de la crítica al permitir modificar el sistema deductivo, identificar nuevos problemas y diferentes soluciones a éstos y a los antiguos.

De allí la importancia de la crítica mutua, rivalidad, hostilidad y amistad entre los biógrafos y también la pertinencia de la configuración de comunidades académicas otorgantes del sentido a las tradiciones académicas en cuyo seno los sistemas deductivos, los problemas y las soluciones tentativas siempre estén bajo la mirada inclemente de la crítica. Pues la biografía así como «La ciencia siempre será una búsqueda, jamás un descubrimiento real. Es un viaje, nunca una llegada ${ }^{65}$. En el género biográfico se parte de problemas, de preguntas. Sea suficiente recordad que «En las ciencias sociales se tiene éxito en proporción exacta a la significación o al interés del problema con el cual estamos tratando».

En el contexto de la crítica mutua entre los biógrafos afloran los intereses con los cuales cada quien aborda su objeto de estudio, o los intereses determinantes al elegir un tipo de biografía. Parte de esos intereses son los denominados extra científicos y los otros, son los llamados, intereses estrictamente científicos. Los primeros están ligados a la vida cotidiana y a la disposición del proyecto de vida de cada individuo y los segundos, expresamente a la ciencia y a sus problemas. Los científicos sociales y en ellos los biógrafos, están abocados a reconocer a ambos, más bien, deben distinguirlos, no mezclarlos. Como no es posible ocultar o desconocer los intereses.

Un biógrafo hace parte de una sociedad, a ella se debe y entre ambas instancias hay una relación biunívoca y dialéctica. No hace parte de un mundo extraño e ideal. Los biógrafos son el resultado de un cúmulo de circunstancias temporales, viven y se desenvuelven en escenarios concretos. Como miembros de una sociedad, en verdad, sienten afectos políticos o rechazan posturas ideológicas, unos más otros menos, expresan sus posiciones políticas, existen quienes alegan ser apolíticos, aunque dicho argumento en sentido estricto, también es una posición política.

Compartimos la tesis según la cual al biógrafo no se le puede despojar de su partidismo y de sus juicios de valor, pero eso no significa la explicación de los resultados de sus trabajos, en última instancia, por su ideología. Naturalmente la militancia política

64 Popper, Karl Raimund. La responsabilidad de vivir: escritos sobre política, historia y conocimiento. Barcelona, Paidós, 1995, 218. 
de un biógrafo puede incidir de distintas maneras en su trabajo. Pero corresponde a él, principalmente, deslindar campos y evitar de esa manera ser presentada su producción científica como panfletos ideológicos y sus comportamientos políticos como la expresión misma de la ciencia. Siempre debe estar presente la crítica, el mismo Popper, identifica el método científico con el método crítico. La crítica en la posición teórica de dicho filósofo es del todo relevante.

Cada ciencia configura su propio objeto, teorías, conceptos, métodos, estrategias comprensivas y explicativas, su lenguaje y niveles de crítica. A partir de ellos emerge tanto los criterios de verdad como de objetividad y, en esa materia, la biografía no es la excepción. No hay ciencias inferiores ni superiores, ni duras ni blandas, simplemente hay ciencias. La ciencia se asume en el pensamiento de este autor como «una rama de la literatura y trabajar en ciencia es una actividad humana como la construcción de una catedral». La ciencia así vista es desacralizada y se pone en el terreno de las acciones humanas sujeta a las virtudes y miserias de éstas.

La comprensión es el resultado de la aproximación a los problemas, desde una perspectiva crítica y de sus soluciones tentativas o provisionales. De igual modo, la comprensión es entender la obra desde la vida ${ }^{66}$. Cuando se comprende un objeto hay conocimiento del mismo. Si los biógrafos, por ejemplo, comprenden una vida, la conocen y la pueden narrar o explicar, y para ello, la literatura es uno de los medios. Pero la comprensión es transitoria, no definitiva, la comprensión entra en crisis cuando se le somete a la crítica y se transita a otra comprensión. En la biografía se actúa a partir de la comprensión previa, se pone a prueba su pertinencia y en esa prueba afloran nuevas circunstancias tornando más compleja la comprensión biográfica.

La comprensión como objeto de las humanidades, tiene varias connotaciones y para explicarlas, me apoyo en la biografía como parte de la historia y ésta como componente de las humanidades. El objeto de la biografía sería la comprensión y la tarea del biógrafo consistiría en propiciar y facilitar esa comprensión. Pero la comprensión de la biografía está mediada por los intereses intra y extra teóricos del biógrafo, es decir, es una comprensión en medio de las existentes. Sobre una biografía existen distintas comprensiones, esas comprensiones en la comunidad de biógrafos deben ser sometidas a la crítica para alcanzar los niveles de objetividad y verdad, si no se someten a la crítica no podrían considerarse como componentes de la biografía.

Cerramos este nutrido elenco de tipos biográfico, con la biografía desde abajo ${ }^{67}$. Esta tipología biográfica no es una exposición de trinchera ni la comprensión contestataria de una vida. Se trata de la decisión política de grupos humanos con características peculiares como ser minorías étnicas, culturales, sexuales, lingüísticas o políticas; o en-

66 Gadamer, Hans-Georg. Verdad y método I. Fundamentos de una hermenéutica filosófica. 5 edición. Salamanca, Sígueme, 1993, 97.

67 Sosa, Ignacio. La Biografía como Arma. En, Revista de Estudios Latinoamericanos. No $4-5$. Universidad de Nariño. Pasto. Colombia. Enero - Junio, Julio - Diciembre, 1999. 
contrarse en condición de desempleo, subempleo, bajos ingresos, represión y exclusión por parte de un sistema político y con problemas como la insalubridad, el analfabetismo, el hambre, la falta de vivienda, éxodos y la falta de oportunidades o, simplemente, identificarse con un personaje y considerarlo su más genuino representante como se infiere de la "Biografía de S. E. el Presidente de la República de Chile Dr. Salvador Allende"68.

Estos grupos organizadamente pueden elaborar sus propias biografías, como un ejercicio sociológico, político, ideológico, cultural, psicológico, conducente a conocerse a través de sus propios procesos mentales, palparse con sus propias manos y verse con sus propios ojos y desde esa práctica de diagnóstico crítico reconocerse como sujetos portadores de conciencia histórica propiciando la comprensión del sentido de sus vidas en el pasado, para actuar en el presente y pensar en el futuro. Si se quiere, se trata de la biografía y de la historia puesta al servicio de grupos sociales específicos, interesados en afrontar los problemas de la vida, a partir del conocimiento de ésta emanado de sus propias facultades. Los biógrafos, los historiadores y los intelectuales en general, deberían animar estos procesos. Hacerlo o no, también implica una práctica y una posición política por parte de éstos.

De los anteriores tipos, es perceptible la afinidad entre la variedad biográfica oral y desde abajo, con referencia a la biografía novelada, tendenciosa, psicológica e histórica; aclarando que toda biografía es, por su misma naturaleza, una forma de investigar, narrar, escribir, publicar y leer la historia.

\section{CONCLUSIONES}

Como se puede observar, los tipos de biografías señalados por Romero, Gajardo, Edel y Velásquez son pautas que permiten fortalecer el género biográfico. La intención de marcar la especificidad de cada uno de ellos es señalarle al biógrafo, el amplio universo dentro del cual puede actuar, pero a su vez se trata de hacer un llamado sobre el riesgo subyacente de las biografías elaboradas, en forma estricta, desde un solo punto de vista o tipo biográfico, pues ello supondría mutilar una vida para acomodarla dentro de unos marcos, generalmente estrechos y, por ello, mismo terminará haciéndose una parodia de biográfica desde diferentes dimensiones.

La biografía es un invaluable recurso intelectual en el ámbito de las Ciencias Humanas y Sociales. De igual modo, la biografía desborda las a veces caprichosas especificidades de las disciplinas del conocimiento y es, por antonomasia, interdisciplinaria. Esta última característica no riñe con ninguno de los tipos de biografía, por el contrario, es parte de su fortaleza.

68 Liddell, Robert. Kavafis: una biografía crítica. Barcelona: Ediciones Ultramar, 1989, segunda edición, 155. 
De igual modo, la biografía, dada su larga trayectoria, como cualquier campo del saber procura consolidar sus metodologías y teorías, siempre en constante formación. Lo anterior supone, la pluralidad de criterios que animan al biógrafo y la amplitud de formas y perspectivas para adelantar su trabajo.

Es así mismo la biografía, un genuino mecanismo para la educación en todas las culturas y edades de los individuos. A través de ella, es posible formar seres humanos sensibles a la grandeza de los pueblos, en el marco de la tolerancia, el apego a la civilidad $\mathrm{y}$ al respeto a la vida. 


\section{BIBLIOGRAFÍA}

Aburto Prieto, Fabiola. Biografía oral: los rostros de Menecio Antúnez. En: La Segunda (Diario: Santiago de Chile) Noviembre 30, 2019.

Basler, Roy Prentice. Lincoln: biografía completa e ilustrada del más glorioso presidente norteamericano. México: Limusa, 1966.

Biografía Universal: antigua y moderna o historia por orden alfabético de la vida pública y privada de todas las personas distinguidas por sus escritos, acciones, talentos, virtudes o vicios. (Traducción del francés al castellano, con adiciones y refundiciones por Javier de Burgos. Madrid: Impr. de Mateo Repullés, 1822, 3 volúmenes.

Brémond, Henry. Newman. Ensayo de biografía psicológica. Buenos Aires, Desclée de Brouwer, 1947.

Castillo Didier, Miguel. Juan Bautista Plaza: una vida por la música y Venezuela (ensayo de biografía documental). Caracas: Instituto Latinoamericano de Investigaciones y Estudios Musicales Vicente Emilio Sojo. 1985.

Collier, David. Método comparativo. En: Revista Uruguaya de Ciencia Política. № 5. Instituto de Ciencia Política. Facultad de Ciencias Sociales. Universidad de la República. Montevideo, 1992.

Clarke, Desmond M. Descartes: a biography. Cambridge University Press. 2006.

Cronin, Vincent. Napoleón: una biografía íntima. (Traducción, Anibal Leal). Buenos Aires: Vergara Grupo Zeta, 2003.

Chamberlain, Lesley. Nietzsche in Turin: an intimate biography. St Martin's Press, 1997.

Daza N, Loreto. Piñera: biografía no autorizada. Santiago de Chile; Penguin Random House, 2017.

Edel, León. Vidas ajenas. Principia Biographica. Buenos Aires: Fondo de Cultura Económica, 1990.

Gadamer, Hans-Georg. Verdad y método I. Fundamentos de una hermenéutica filosófica. 5 edición. Salamanca, Sígueme, 1993.

Gajardo, Samuel. Cómo expresar la vida de un hombre. O la manera de escribir una biografía. Santiago, Universo, 1944.

Gamow, George. The Great Physicists from Galileo to Einstein. Dover Publications Inc., 2003.

González, Luis. De la múltiple utilización de la Historia. En: Pereyra, Carlos et al. Historia, ¿Para Qué? 6 edición, México, Siglo XXI, 1985.

Grawitz, Madeleine. Bakounine: biographie. Calmann-Lévy. 2000.

Herrero, Víctor. Agustín Edwards Eastman: una biografía desclasificada del dueño de El Mercurio. Santiago de Chile: Penguin Random House, 2014.

Jacob Abdelnour, Ruth Elsa. Raíces de arena y olvido: biografía y autobiografía novelada de las familias Jacob Bendeck, Abdelnour Salamé y Jacob Abdelnour. Santiago, 2008.

Janoska-Bendl, Judith. Max Weber y la sociología de la historia, Buenos Aires, Sur, 1972. 
Jiménez, Gustavo. Josyane Savigneau, la invención de una biografía. En: La Época (Diario: Santiago, Chile). Agosto 7 de 1992.

Liddell, Robert. Kavafis: una biografía crítica. Barcelona: Ediciones Ultramar, 1989, segunda edición.

Losurdo, Domenico. Antonio Gramsci: del liberalismo al "comunismo crítico". (Juan Vivanco, Traductor). Madrid: Disenso, 2015.

Magris, Claudio. Biografía y novela. En, Revista de Occidente. № 220. Madrid. Septiembre 1999.

Morlino, Leonardo. Problemas y opciones en la comparación. En: La comparación en las Ciencias Sociales. Giovanni Sartori y Leonardo Morlino (eds.). Madrid, Alianza, 1994.

Morner, Magnus. Ensayos sobre historia latinoamericana. Biblioteca de Ciencias Sociales. Volumen 37. Universidad Andina Simón Bolívar. Quito, 1992.

Ott, Hugo. Martin Heidegger: en camino hacia su biografía. (Traducción Helena Cortés Gabaudan). Madrid: Alianza, 1992.

Payette, Jean-Francois. Lawrence, Olivier. Albert Camus: Nouveaux regards sur sa vie et son oeuvre. Presses de l'Université du Québec. 2007.

Piña, Carlos. Sobre las historias de vida y su campo de validez en las ciencias sociales. Documento de Trabajo. Programa Flacso. Santiago de Chile. № 319. Santiago. Octubre de 1986.

Plutarco. Vidas paralelas I. Teseo-Rómulo. Licurgo-Numa. Introducción general, traducción y notas por Aurelio Pérez Jiménez. Madrid, Gredos, 2000.

Popper, Karl Raimund. La responsabilidad de vivir: escritos sobre política, historia y conocimiento. Barcelona, Paidós, 1995.

Romero, José Luis. Sobre la biografía y la historia. Buenos Aires, Sudamérica, 1945.

Sartori, Giovanni. Comparación y método comparativo. En: La comparación en las Ciencias Sociales. Giovanni Sartori y Leonardo Morlino (eds.). Madrid, Alianza, 1994.

Sociedad de Publicaciones Religiosas. Martin Lutero: biografía auténtica. Madrid: Sociedad de Publicaciones Religiosas, 1893.

Sosa, Ignacio. La Biografía como Arma. En, Revista de Estudios Latinoamericanos. N ${ }^{\circ}$ 4 - 5. Universidad de Nariño. Pasto. Colombia. Enero - Junio, Julio - Diciembre, 1999.

Suetonio Tranquilo, Cayo. Los doce Césares. (Norberto Castilla, Traductor). Madrid: Páez y Cía, 1917.

Tong, Hollington K. La biografía en fotos del Presidente Chiang Kai Shek. China: Government Infomation off, 1972.

Unidad Popular. Biografía de S. E. el Presidente de la República de Chile Dr. Salvador Allende. Santiago de Chile, Ministerio de Relaciones Exteriores, Departamento de Impresos, 1970.

Vega Cantor, Renán. Historia: conocimiento y enseñanza. Bogotá, Antropos, 1988. 
Velásquez Rivera, Edgar. La biografía, Popayán, Diseño Gráfico e Impresiones, 2007. Veuillot, Louis. Biografía del Papa Pío IX. Madrid: Impr. de la Esperzanza. 1863.

Vircondelet, Alain. Jean-Paul II: la biographie. First. 2004.

Zweig, Stefan. Magallanes: el hombre y su gesta. (Traducción de Editorial Juventud). Barcelona: Random House Mondadori, 2005. 